\title{
Subjetividade e prática profissional: processos subjetivos de uma psicóloga hospitalar com pacientes com câncer
}

Esta apresentação apresenta reflexões com base em uma pesquisa realizada cujo objetivo foi compreender processos subjetivos da prática profissional de uma psicóloga que trabalha com pacientes com câncer. Nesse processo investigativo, buscou-se compreender recursos subjetivos gerados pela psicóloga no processo de sua formação profissional, bem como explicar sentidos subjetivos produzidos nas relações com os pacientes. Num primeiro momento, a noção de câncer é discutida a partir de uma perspectiva histórica, enfatizando sua representação no contexto do modelo biomédico, que a reduz a um adoecimento do corpo biológico. Posteriormente, discute-se o processo de câncer em crianças e adolescentes, abordando processos psicológicos interligados nessa fase do ciclo vital. Num segundo momento, a noção de saúde é compreendida a partir da integralidade de todos os aspectos que possam envolver tal enfermidade, tais como aspectos relacionais, emocionais, psicológicos e biológicos; a criação da noção da instituição hospitalar na contemporaneidade e a noção da psicologia da saúde, destacando a psicologia da saúde crítica. A partir destes desdobramentos, compreende-se a importância do brincar no contexto hospitalar e de internação, pois visa resgatar a sociabilidade e a fantasia que possam se perder durante o processo e promover a elaboração de conteúdos que possam provocar sofrimento psíquico. O brincar promove oportunidades de expressar sentimentos acumulados de tensão, frustração, insegurança e agressividade. E finalmente, discute-se a partir do histórico de formação da instituição hospitalar, no modo industrial o qual se desdobra em um sistema de assistência em saúde em que os saberes e as práticas de cura são ligados a alienação do indivíduo e isto acaba gerando uma dependência direta dos profissionais de saúde. Após esse aporte histórico da instituição hospitalar, a psicologia da saúde é definida como um campo autônomo para promoção e manutenção da saúde, como também a prevenção, identificação e tratamento de doenças. O psicólogo da saúde se fundamenta na promoção de bem estar, respeitando as identidades sociais e encorajar o desenvolvimento das habilidades para alcançar as metas pessoais do paciente. Este presente estudo tem como base epistemológica a Epistemologia Qualitativa, desenvolvida por González Rey, possui uma metodologia específica: o método construtivo- interpretativo que são desdobramentos da teoria da subjetividade. A pesquisa foi realizada com uma psicóloga hospitalar no Hospital de Apoio em Brasília- DF, se trata de uma instituição hospitalar que visa a 
reabilitação física, cuidados paliativos oncológicos, atendimento ambulatorial e outros serviços.Nesta pesquisa, foi utilizada dinâmica conversacional como instrumento, por representar um caráter processual.O diálogo, no método construtivo- interpretativo, é um processo que visa conduzir o indivíduo participante a campos significativos do seu histórico de vida, os quais são capazes de envolvê-la no sentido subjetivo em diferentes espaços delimitados na sua subjetividade individual.

É importante para o profissional, na área hospitalar, desenvolva uma postura ativa tanto com o paciente quanto para o aperfeiçoamento profissional, valorizando o sentir do outro pois se configura como um atendimento humanizado, uma escuta qualificada, ser verdadeira, ser delicada ao comunicar algo para o outro, sendo estes princípios fundamentais na atuação do psicólogo. Para esta pesquisa, o hospital configurou-se como um ambiente que há autonomia e liberdade de atuação, pois não é necessário um espaço determinado para atendimento, como ocorre na clínica tradicional.

Palavras-chaves: Construtivo-interpretativo, psicologia hospitalar, pacientes com câncer. 